\section{Prescription errors in Brazilian hospitals: a multi-centre exploratory survey}

\author{
Erros de prescrição em hospitais brasileiros: \\ um estudo exploratório multicêntrico
}

\author{
${ }_{1}$ Escola de Enfermagem de \\ Ribeirão Preto, Universidade \\ de São Paulo, Ribeirão Preto, \\ Brasil. \\ 2 Faculdade de Enfermagem \\ Nossa Senhora das Graças \\ Universidade de Pernambuco, \\ Recife, Brasil. \\ 3 Faculdade de Enfermagem, \\ Universidade Federal de \\ Goiás, Goiânia, Brasil. \\ 4 Faculdade de Farmácia, \\ Universidade Federal de \\ Sergipe, Aracaju, Brasil. \\ 5 Universidade Camilo \\ Castelo Branco, Descalvado, \\ Brasil. \\ 6 Hospital São Paulo, \\ Universidade Federal de São \\ Paulo, São Paulo, Brasil. \\ Correspondence \\ F. R. E. Gimenes \\ Universidade Camilo Castelo \\ Branco. \\ Rua Bezerra Paes 2358, \\ Descalvado, SP \\ 13690-000, Brasil. \\ fer_gimenes@yahoo.com.br
}

\section{Abstract}

In Brazil, millions of prescriptions do not follow the legal requirements necessary to guarantee the correct dispensing and administration of medication. This multi-centre exploratory study aimed to analyze the appropriateness of prescriptions at four Brazilian hospitals and to identify possible errors caused by inadequacies. The sample consisted of 864 prescriptions obtained at hospital medical clinics in January 2003. Data was collected by three nurse researchers during one week using a standard data sheet that included items about: the type of prescription; legibility; completeness; use of abbreviations; existence of changes and erasures. There were statistically significant differences between incomplete electronic prescriptions at hospital $A$, and handwritten ones from hospitals $C\left(\chi^{2}=12.703\right.$ and $\left.p<0.001\right)$ and $D\left(\chi^{2}=14.074\right.$ and $\left.p<0.001\right)$. Abbreviations were used in more than $80 \%$ of prescriptions at hospitals B, C and D. Changes were found in prescriptions at all hospitals, with higher levels at hospitals B (35.2\%) and A (25.3\%). This study identified a range of vulnerable points in the prescription phase of the medication system at the hospitals. Physicians, pharmacists and nurses should therefore jointly propose strategies to avoid these prescription errors.

Medication Errors; Medication Systems; Drug Prescriptions

\author{
Adriana Inocenti Miasso ${ }^{1}$ \\ Regina Célia de Oliveira ${ }^{2}$ \\ Ana Elisa Bauer de Camargo Silva ${ }^{3}$ \\ Divaldo Pereira de Lyra Junior 4 \\ Fernanda Raphael Escobar Gimenes 5 \\ Flávio Trevisan Fakih 6 \\ Sílvia Helena De Bortoli Cassiani 1
}

\section{Introduction}

Medication errors are a serious public health problem and have received a great deal of attention in recent years. Their effects can range from small injuries to the patient's death and these errors can occur at any stage of the medication system. For these reasons, various studies have aimed to analyze medication systems, detect the most frequent problems, remove the focus from human caused errors and, above all, improve patient safety ${ }^{1,2}$. According to the National Coordinating Council for Errors in Medication Reporting and Prevention (NCCMERP) 3 , a medication error is defined as any preventable event that may cause or lead to inappropriate medication use or patient harm while the medication is in control of the health care professional, patient or consumer.

Between 1983 and 1993, medication errors occurred in $5 \%$ of all hospital admissions in the United States. This same period saw a $257 \%$ increase in drug-related deaths 4 . The Institute of Medicine estimated that 7,000 Americans die annually due to medication errors ${ }^{5}$. In the United Kingdom, medication error is one of the most common causes of unintentional harm which results in an estimated 85,000 hospital admissions every year 6 . These errors were responsible for approximately $5 \%$ of hospitalizations in Spain, with an average cost of 3,000 Euros per patient 7 . Moreover, it is estimated that 80,000 incidents 
and errors occur in Australia with costs of at least US\$350 million per year 8 .

In South America the situation is no different. An observational study carried out in Colombia between 1993 and 2006 demonstrated that the main types of medication errors caused death (45\%) or harm (47.3\%) to patients 9 . In Argentina, two studies in public hospitals estimated that there are errors in two out of every ten medication indications 10 . One study in Uruguay showed that the majority of resident doctors do not have sufficient knowledge about doses, adverse reactions and contraindications of drugs 11 .

The discussion about medication errors in Brazil is still incipient and few articles have been published 1,2,12,13. Medication errors accounted for $50 \%$ of adverse events detected in a study carried out in a private hospital in the city of Campinas (São Paulo State) 14. In anoother study performed in a public hospital in the city of Belo Horizonte (Minas Gerais State), 82\% of 422 prescription order forms presented at least one dispensing error 15 . Administrative errors represented about $27 \%$ of adverse events identified in a Brazilian multi-centre study 16. In 2001, the National Sanitary Surveillance Agency (ANVISA) created a project, called the Sentinel Hospitals, to reduce these problems and try to build a reference network for hospitals that will provide data on adverse events 2 .

The medication system is multidisciplinary and includes prescribing, dispensing, administering and monitoring. Although various health care providers are involved in this system, these processes should be harmonized to ensure patient safety. The medication system starts with the prescription. Any flaw at this stage can directly or indirectly lead to problems in subsequent stages, increase medication error statistics and affect patient safety.

According to Bobb et al. 17, the incidence of prescribing errors in the United States has been reported to range from three to 99 errors per 1,000 inpatient medication orders. In Brazil, every year, millions of prescriptions do not follow the legal requirements that are necessary to guarantee correct dispensing and administration of medication 18. Moreover, different studies have shown that the inadequacies of prescriptions and the difficulties in understanding them risk patient safety 1,15,19. Therefore, the aims of this study were to analyze the quality of prescriptions at four Brazilian hospitals and to identify possible errors caused by inadequacies.

\section{Methodology}

\section{Study design}

This multi-centre exploratory survey sought to collect detailed descriptions of the variables which are included in medical prescriptions at different Brazilian hospitals.

\section{Settings}

The research was carried out at the medical clinics of four university hospitals located in Goiânia (Goiás State), Recife (Pernambuco State), Ribeirão Preto and São Paulo (both São Paulo State), described in the text as hospitals A, B, C and $D$, in which the sequence of letters does not correspond to the order of cities shown above.

The choice of these institutions was made because they are linked to state or federal public universities and they are part of the ANVISA Sentinel Hospital Network. Furthermore, a Sentinel Hospital Network was created as a national net pilot test, which has more than 100 hospitals involved. These hospitals were chosen for having a larger number of medical residence programs per state. Notification of adverse drug events is encouraged in order to gather as much information as possible, so the government is able to regulate medicines and medical commerce 16

The medical clinics were selected because they assign beds for patients with chronic-degenerative diseases, whose treatment usually involves a wide range of drugs over a long period of time.

\section{Sample}

The study sample consisted of 864 prescriptions for patients hospitalized at the medical wards, during one week in January 2003. From this total, 110 were from hospital A, 108 from B, 294 from $\mathrm{C}$ and 248 from hospital D. All prescriptions observed were used in the study and there were no exclusions.

\section{Data collection procedures}

After participating in 20 hours of training sessions, three nurse researchers collected data at each of the hospitals. Data was collected in close proximity to the nursing staff and always at the end of the afternoon, during seven consecutive days 17,20,21 through a structured instrument developed by the group of researchers, based on the literature 22 , with items about the type of medication prescription (electronic or handwritten), legibility (legible, illegible or partially printing), 
completeness of prescriptions (complete or not complete), abbreviations (present or not present) and existence of changes and erasures. It is important to highlight that illegible prescriptions or unmarked items were not included in the other analysis.

The nurse researchers visited the wards to revise all prescriptions issued by physicians during the morning, and filled out the standard data sheet.

\section{$\underline{\text { Data analysis }}$}

The prescriptions were analyzed as follows:

- Type of prescription: whether electronic or handwritten;

- Legibility: the difficulty in interpreting the content of prescriptions, according to all three researchers, and requiring further clarification with the prescriber and/or a review of the charts 17 . The electronic and handwritten prescriptions were classified as: legible, partially illegible and illegible. The researchers built a protocol based on the literature and Brazilian regulations to judge these prescriptions 18,23. During the data collection, the researchers tried to read the prescriptions and discussed its legibility. Decisions were made by consensus; however, when consensus couldn't be reached, majority voting was applied;

- Completeness: the prescription was considered complete when the following criteria were all present: patient identification, presence of date (present or not present), prescriber signature; time indications (correct time, complete time, legible or without erasures), the name of the medicine, dosage form, route of administration and dose 18,24;

- Abbreviations: whether yes or no. The abbreviations were checked in relation to the: dosage form - comp (tablets), amp (flask), caps (capsules); route of administration - VO (administered orally), IV (intravenous); and units - IU (mg, g, $\mathrm{mL}$, etc.);

- Changes: any modifications in items of prescriptions were observed, such as: the name of the medicine, dosage form, route of administration, dose and duration of treatment;

- Erasures: were considered to be any item that negatively affected the understanding of prescribed items, whether caused by erasures, overlapping, and use of correctors, tape or spatters.

\section{Statistical analyses}

The data was analyzed using SPSS 11.0 (SPSS Inc., Chicago, U.S.A.). Absolute frequencies were described as percentages. Chi-square analysis was used to evaluate associations in different hospital characteristics $(\mathrm{p}<0.001)$.

\section{Ethical aspects}

This study was approved by the Research Ethics Committees and authorized by the directors of the four hospitals in the study. The purpose of the present work was neither to find out nor to identify the professional that committed the flaw, but to analyze and detect the prescription errors, making the medication system safer for its users. Therefore, the collected data was used exclusively by the researchers, guaranteeing the privacy of the information obtained.

\section{Results}

Although all prescriptions are produced electronically at hospital A, handwritten changes to existing medications and the inclusion of new drugs occurred in $22 \%$ of cases. This was possible because the computer system does not permit changes after the electronic prescription printout. Handwritten prescriptions were still used at the three other hospitals. Moreover, $12 \%$ of prescriptions at hospital B, 35.5\% at hospital C and $12 \%$ at hospital D were considered fully or partially illegible, mainly due to the physician's handwriting. At hospital C, for example, $7 \%$ of the 294 prescriptions examined were illegible and $28.5 \%$ partially illegible (Table 1 ).

It is important to highlight that the illegible prescriptions were not included in the other statistics. In this study, only hospital A used generic names for drugs in all prescriptions. The highest number of complete prescriptions was found at hospital D (38\%).

Incomplete prescriptions were most common at hospital C (94.5\%), followed by hospital B (88\%). Also, there were statistically significant differences between hospital A, with electronic prescriptions, and $C\left(\chi^{2}=12.703\right.$ and $\left.p<0.001\right)$ and $\mathrm{D}\left(\chi^{2}=14.074\right.$ and $\left.\mathrm{p}<0.001\right)$.

Among more missed items, the dosage form was common in $87 \%$ of prescriptions at hospital $\mathrm{B}$ and $77 \%$ at C. Moreover, less than half of the prescriptions at hospitals A, C and D informed what medication doses were to be administered. Information about routes of administration was missing in $3.5 \%$ of prescriptions at hospital A and 5.5\% at hospital C. Only at hospital B did all prescriptions contain information on dose and route of administration. Abbreviations were used in more than $80 \%$ of prescriptions at hospitals B, $\mathrm{C}$ and D, against $30 \%$ at hospital A. Most of these abbreviations were for routes of administration, 
Distribution of drug prescriptions analyzed per hospital and specification of content characteristics, from December 2002 to January 2003.

\begin{tabular}{|c|c|c|c|c|c|c|c|c|}
\hline \multirow[t]{3}{*}{ Specifications } & \multicolumn{8}{|c|}{ Hospitals } \\
\hline & \multicolumn{2}{|c|}{$A(n=110)$} & \multicolumn{2}{|c|}{$B(n=108)$} & \multicolumn{2}{|c|}{$C(n=294)$} & \multicolumn{2}{|c|}{$D(n=248)$} \\
\hline & $\mathbf{n}$ & $\%$ & $\mathrm{n}$ & $\%$ & $\mathrm{n}$ & $\%$ & $n$ & $\%$ \\
\hline \multicolumn{9}{|l|}{1 - Legibility } \\
\hline Legible printing/written & 108 & 98.0 & 95 & 88.0 & 190 & 64.5 & 219 & 88.0 \\
\hline Illegible printing/written & - & - & 3 & 3.0 & 20 & 7.0 & 2 & 1.0 \\
\hline Partially illegible printing/written & 2 & 2.0 & 10 & 9.0 & 84 & 28.5 & 27 & 11.0 \\
\hline \multicolumn{9}{|l|}{2 - Nomenclature } \\
\hline Brand name & - & - & 1 & 1.0 & 121 & 41.0 & 92 & 37.0 \\
\hline Generic name & 110 & 100.0 & 1 & 1.0 & - & - & 1 & 0.5 \\
\hline Brand and generic name & - & - & 106 & 98.0 & 172 & 58.5 & 155 & 62.5 \\
\hline \multicolumn{9}{|l|}{3 -Completeness of prescription } \\
\hline Complete & 19 & 17.3 & 13 & 12.0 & 16 & 5.5 & 94 & 38.0 \\
\hline Incomplete & 91 & 82.7 & 95 & 88.0 & 278 & 94.5 & 154 & 62.0 \\
\hline \multicolumn{9}{|c|}{4 - Incomplete prescriptions: most missing items * } \\
\hline Dosage form & 33 & 30.0 & 94 & 87.0 & 222 & 77.0 & 107 & 43.1 \\
\hline Dose & 49 & 44.5 & - & - & 66 & 23.0 & 76 & 31.0 \\
\hline Administration route & 4 & 3.5 & - & - & 19 & 5.5 & - & - \\
\hline \multicolumn{9}{|l|}{5 - Abbreviations } \\
\hline Present & 33 & 30.0 & 92 & 85.0 & 264 & 89.8 & 248 & 100.0 \\
\hline Not present & 70 & 63.5 & 16 & 15.0 & 16 & 5.4 & - & - \\
\hline
\end{tabular}

* The number of items does not correspond to the number of prescriptions, as one or more of the investigated items were missing in some prescriptions. Note: $p<0.001$

such as EV (intravenous administration) and VO (oral administration), which were more frequent at hospitals $\mathrm{C}$ and $\mathrm{D}$.

Changes were found in prescriptions at all hospitals, with higher levels at hospitals B (35.2\%) and A (25.3\%), followed by hospitals C (16.6\%) and $\mathrm{D}(9.6 \%)$. The interruption of ongoing medication was most frequent at hospital B (35.2\%). Other and less frequent alterations referred to substituted drugs, handwritten changes in posology, time and routes of administration, as well as modifications in other items (Table 2).

At hospital A, $19 \%$ of prescriptions contained erasures, $12 \%$ at B, $29.9 \%$ at $\mathrm{C}$ and $16.9 \%$ at D, mainly in posology ( $8.3 \%$ at hospital B and $7.5 \%$ at $\mathrm{C}$ ). This data showed that there were no statistically significant differences between the hospitals $\left(\chi^{2}=6.258, p=0.745\right)$. Moreover, $100 \%$ of the electronic prescriptions in hospital A were frequently dated in comparison with about $96 \%$ of handwritten patient prescriptions, at B and C. At hospital D, $17 \%$ of prescriptions did not have a date.

Other analysis showed that all study hospitals adopted an institutional standard to determine time indications, which was established by a clerk at hospital $\mathrm{A}$, the nurse or nurse resident at $\mathrm{B}$, a member of the nursing team at $\mathrm{C}$ and nursing auxiliaries at D. Correct times (100\%), complete times (98\%) and legible time indications (99\%) were most frequent at hospital B. The lowest number of erasures in time indications was found at hospital D (91\%).

\section{Discussion}

This study provides evidence that prescribing errors are common in different Brazilian hospitals. The international literature describes that the implementation of an electronic prescriptions system, as used in hospital A, brings important advantages to medication safety and it improves drugs logistics 20,21,25,26. According to Koppel et al. 27, the electronic prescription is one way of modernizing, simplifying and making the medication system safer, partially because it eliminates the problem of legibility, reduces errors and provides greater safety for medication distribution and administration. These prescriptions, credited with lowering medication errors by up to $81 \%$ eliminate mistakes due to illegible handwriting, and reduce the likelihood of errors that stem from drugs with similar names 17. 
Distribution of drug prescriptions in terms of changes made, date and timing, from December 2002 to January 2003.

\begin{tabular}{|c|c|c|c|c|c|c|c|c|}
\hline \multirow[t]{3}{*}{ Changes and types } & \multicolumn{8}{|c|}{ Hospitals } \\
\hline & \multicolumn{2}{|c|}{ A } & \multicolumn{2}{|c|}{ B } & \multicolumn{2}{|c|}{ C } & \multicolumn{2}{|c|}{ D } \\
\hline & $\mathbf{n}$ & $\%$ & $\mathbf{n}$ & $\%$ & n & $\%$ & $\mathbf{n}$ & $\%$ \\
\hline \multicolumn{9}{|l|}{1 - Types of changes } \\
\hline Interrupted medication & 12 & 10.9 & 38 & 35.2 & 5 & 1.7 & 16 & 6.4 \\
\hline Replaced medication & - & - & - & - & 44 & 14.9 & 6 & 2.4 \\
\hline Changes in administration route & - & - & - & - & - & - & 2 & 0.8 \\
\hline Handwritten modifications to dose & 4 & 3.6 & - & - & - & - & - & - \\
\hline Handwritten modifications to time & 3 & 2.7 & - & - & - & - & - & - \\
\hline Handwritten modifications to other prescription items & 9 & 8.1 & - & - & - & - & - & - \\
\hline \multicolumn{9}{|l|}{2 - Presence of date } \\
\hline Present & 110 & 100.0 & 103 & 95.4 & 284 & 96.6 & 205 & 82.7 \\
\hline Not Present & - & - & 5 & 4.6 & 3 & 1.0 & 43 & 17.3 \\
\hline \multicolumn{9}{|l|}{3 - Time indications } \\
\hline Correct time & 98 & 89.9 & 108 & 100.0 & 295 & 93.5 & 236 & 95.1 \\
\hline Complete time & 107 & 92.7 & 106 & 98.1 & 269 & 91.5 & 235 & 94.7 \\
\hline Legible & 106 & 96.3 & 107 & 99.0 & 265 & 90.1 & 203 & 81.8 \\
\hline Without erasures & 96 & 87.2 & 84 & 77.7 & 255 & 86.7 & 226 & 91.1 \\
\hline
\end{tabular}

Note: $p<0.001$

However, some studies have demonstrated that an electronic prescription system can minimize but does not fully eliminate the possibility of errors 19,20. These risks can increase when, in this study, the handwritten modifications were done to interrupt actual medications or to include new drugs. It is also expensive to establish such a system, even by international standards, which is an impediment for a number of institutions.

On the other hand, at hospital B, the nurse or a clerk transcribed all prescriptions in the computer in order to request the medication from the pharmacy. At hospitals C and D a copy of the physician's handwritten prescription was sent to the pharmacy, while the original was kept inside the patient's records. Although this system can avoid transcription errors, the copy handled by the pharmacy is not always legible. According to the literature, this practice causes serious risks of dose errors, route and dosage form, for example, as illegible handwriting may, in the worse case scenario, lead to a patient's death 22,28 . In almost all cases, errors caused by illegible handwritten prescriptions could be preventable, thus, efforts from universities and ANVISA are necessary to qualify prescribers and eliminate this problem from the Sentinel Hospitals Network.

When the presence of a generic name in prescriptions was analyzed, the present study findings show that only hospital A complies with the obligation of using it, mainly due to the use of an electronic prescription system, although the use of generic medication names is obligatory on all prescriptions issued in the Brazilian Unified National Health System (SUS).

In view of similar names, labels and packages, the lack of a standard for using generic or brand names is an important risk factor that can lead to a series of errors in the subsequent stages of the medication system 29 . At the same time, prescribing commercial brands makes treatment more expensive. This is a relevant fact, as high drug costs have been indicated as the cause of omission errors and as a limiting factor for medication treatment adherence, mainly in middle-income countries such as Brazil 19,20. The literature mentions the use of both generic and brand names as the most advisable and safe approach to avoiding system errors 29 .

According to the results, missing items were another common problem observed in prescriptions. The international and national standards recommend that all prescriptions clearly include important information such as the dosage form, dose and route of administration 18,24 . When prescriptions are not complete, it may cause serious risks to patient safety. In this study, few prescriptions analyzed contained the correct and complete specifications, which are paramount for treatment success. These 
findings corroborate other previous studies and demonstrate the need to restructure the medication process to avoid omission of information in prescriptions 30,31 . The literature affirms that most hospitals do not have a computerized physician order entry system yet, and for this reason the incorporation of the pharmacist into the health care team is a more feasible alternative to checking prescription completeness to avoid these errors 14,30,31.

All hospitals, in this study, permitted the use of abbreviations. Although it saves time and space, using abbreviations may sometimes turn out to be very expensive, as they may be misinterpreted, have double meanings, be confusing and give rise to errors $32,33,34$. Some studies mentioned difficulties in making the following distinctions on handwritten prescriptions: comp (tablets) vs. amp (flask); caps (capsules) vs. comp (tablets); sup (suppositories) vs. susp (suspension), which can lead to incorrect routes of administration and/or techniques 19,31,35. In 2007, ANVISA discussed the establishment of standards for abbreviations in prescriptions 36 . Hence, prescribers should avoid frequent abbreviations and, if necessary, only use standardized versions 37,38. Moreover, electronic prescriptions can also eradicate the use of abbreviations 21 .

As mentioned in the above results, handwritten changes in electronic prescriptions were observed at hospital A. Gimenes et al. 20 described that doctors and residents pointed out the difficulty of introducing new information as a disadvantage of electronic prescriptions. Koppel et al. 27 recognized that the inflexibility of electronic prescriptions, with regard to any kind of nonstandard changes, can generate new error risks. The interruption of prescriptions was the most common change found in this study and it occurred at all hospitals, including hospital A. This data was confirmed by the literature that demonstrated that interruptions of the drug regimen were not reduced by electronic prescriptions 35,39 . So, Lesar 28 highlighted the need to confirm prescription changes or interruptions, from the discussion between the pharmacist and physician.

Also, the results showed that there were no statistically significant differences between erasures made at the prescriptions in all hospitals ( $p<0.001)$. It may cause confusion, which goes against the Brazilian medical ethics code which establishes that the doctor is responsible for prescribing clearly and legibly and, therefore, without erasures 40 . Despite this, previous studies showed that erasures are common in Brazilian prescriptions $13,20,35$. Sometimes a 'free text' feature can be used to substitute erasures in prescriptions. However, this alternative has to be evaluated by the pharmacist or nurse for both logistical and safety reasons 26

Analyzing the inclusion of dates in Brazilian hospital prescriptions, the results differ from another study, carried out in a walk-in clinic, where only $47 \%$ of handwritten prescriptions were dated 19 . The omission of this information may cause the interruption of drug administration before the foreseen treatment duration. In the case of antibiotics, for instance, the interruption before the foreseen treatment duration may cause bacterial resistance and the inability to use subsequently the same antimicrobial agent 30 .

Researchers in this area reject approaches that focus on health care providers as the single cause of errors and assert that systematic changes are the most effective strategy to reduce the probability of accidents 41,42 . Based on this, nurses and pharmacists, although they are not directly responsible for prescribing drugs, should know all aspects and phases involved in the process, collaborating with physicians to prevent errors that negatively affect the patients 26 . Moreover, these health care providers can be considered jointly responsible for ensuring patient safety 28

\section{Study limitations}

There were several limitations to our study. It was conducted over a 1-week period in four Sentinel Hospitals. These results may not be generalizable to other hospital settings where there are no medical residency programs. There is a chance that during this week prescribing errors occurred more frequently than they occur on average. The study was not designed or powered to identify differences in the types of errors. Future works should be designed to focus on these differences.

\section{Conclusions}

This study demonstrates that most prescriptions from four hospitals investigated were inadequate in terms of legibility, use of abbreviations and omitted items, entailing serious risks for patient safety. The gravity of this situation is worsened by the fact that the four hospitals are referral institutions in the SUS and, mainly, responsible for training future health care providers.

We identified a range of vulnerable points in the prescription phase of the medication system at the study hospitals. Therefore, physicians, pharmacists and nurses should work together, discuss and propose strategies to avoid the most common prescription errors, contributing to the structure of a safer medication system for Brazilian patients. 


\section{Resumo}

No Brasil, milhões de prescrições não apresentam os requisitos legais necessários para garantir a correta dispensação e administração dos medicamentos. Este estudo multicêntrico exploratório objetivou analisar a adequação das prescrições em quatro hospitais brasileiros e identificar eventuais erros causados pelas inadequações. A amostra consistiu de 864 prescrições obtidas nas clínicas médicas dos hospitais em janeiro de 2003. Os dados foram coletados por três enfermeiras durante uma semana através de instrumento estruturado com variáveis sobre: tipo de prescrição; legibilidade; completude; presença de abreviações, alterações e rasuras. Houve diferenças estatisticamente significativas entre prescrição eletrônica no hospital A e manuscritas nos $C\left(\chi^{2}=12,703\right.$ e $\left.p<0,001\right)$ e $D$ $\left(\chi^{2}=14,074\right.$ e $\left.p<0,001\right)$. Abreviações foram usadas em mais de $80 \%$ das receitas nos hospitais B, C e D. Alterações foram encontradas em prescrições de todos os hospitais, com níveis mais elevados no B $(35,2 \%)$ e A (25,3\%). Este estudo identificou uma série de pontos vulneráveis na fase prescrição dos sistemas de medicação dos hospitais. Portanto, médicos, farmacêuticos e enfermeiros deverão juntos propor estratégias para evitar erros de prescrição.

Erros de Medicação; Sistemas de Medicação; Prescrição de Medicamentos

\section{Contributors}

A. I. Miasso, R. C. Oliveira, F. T. Fakih and A. E. B. C. Silva were responsible for gathering, analyzing and interpreting the data; as well as revising the article and for the final approval of the version to be published. D. P. Lyra Junior and F. R. E. Gimenes were responsible for interpretation of the data, drafting the article and for the final approval of the version to be published. S. H. B. Cassiani was the coordinator of the multi-centre study, assisting the gathering, analysis and interpretation of data and was responsible for the final approval of the version to be published.

\section{Acknowledgments}

The authors wish to thank the Brazilian Council for Scientific and Technological Development (CNPq) and the São Paulo State Research Foundation (FAPESP) for financial support.

\section{References}

1. Carvalho VT, Cassiani SHB, Chiericato C, Miasso AI. Erros mais comuns e fatores de risco na administração de medicamentos em unidades básicas de saúde. Rev Latinoam Enferm 1999; 7:67-75.

2. Rosa MB, Perini E. Erros de medicação: quem foi? Rev Assoc Med Bras 2003; 49:335-41.

3. National Coordinating Council for Medication Error Reporting and Prevention. What is medication error? http://www.nccmerp.org/council/coun cil1996-09-04.html (accessed on 14/Sep/2005).

4. Bond CA, Raehl CL, Franke T. Medication errors in United States hospitals. Pharmacotherapy 2001; 21:1023-36.

5. Kohn LT, Corrigan JM, Donaldson MS, editors. Institute of Medicine report. To err is human: building a safer health system. Washington DC: National Academies Press; 1999.

6. Timbs O. Leading role for pharmacists to reduce drug errors and improve patient safety. Pharm J 2002; 268:39.

7. Otero-López MJ. Nuevas iniciativas para mejorar la seguridad de la utilización de los medicamentos en los hospitales. Rev Esp Salud Pública 2004; 78:323-39.

8. Roughead EE. The nature and extent of drug-related hospitalisations in Australia, 1999. J Qual Clin Pract 1999; 19:19-22.

9. Paredes NM, Parras MEO. Errores de medicación en los profesionales sanitarios y sus consecuencias médico legales. Rev Méd Legal 2006; 13:24-9.

11. Giachetto G, Banchero P, Telechea H, Speranza N, Wolaj M, Toledo M, et al. Uso racional de medicamentos: ¿qué conocen los médicos residentes sobre los fármacos de uso corriente? Rev Med Urug 2003; 19:231-6.

12. Kawano DF, Pereira LRL, Ueta JM, Freitas O. Acidentes com os medicamentos: como minimizálos? Rev Bras Ciênc Farm 2006; 42:487-95.

13. Miasso AI, Grou CR, Cassiani SHB, Silva AEBC, Fakih FT. Erros de medicação: tipos, fatores causais e providências tomadas em quatro hospitais brasileiros. Rev Esc Enferm USP 2006; 40:524-32. 
14. Monzani AAS. A ponta do iceberg: o método de notificação de erros de medicação em um hospital geral privado no município de Campinas-SP [Dissertação de Mestrado]. Escola de Enfermagem de Ribeirão Preto, Universidade de São Paulo; 2006.

15. Anacleto TA, Perini E, Rosa MB, César CC. Drugdispensing errors in the hospital pharmacy. Clinics 2007; 62:243-50.

16. Miasso AI, Silva AEBC, Cassiani SHB, Grou CR, Oliveira RC, Fakih FT. O processo de preparo e administração de medicamentos: identificação de problemas para propor melhorias e prevenir erros de medicação. Rev Latinoam Enferm 2006; 14:354-63.

17. Bobb A, Gleason K, Husch M, Feinglass J, Yarnold PR, Noskin GA. The epidemiology of prescribing errors: the potential impact of computerized prescriber order entry. Arch Intern Med 2004; 164:785-92.

18. Ministério da Saúde. Lei no ${ }^{\circ}$ 5.991. Dispõe sobre o controle sanitário do comércio de drogas, medicamentos, insumos farmacêuticos e correlatos, e dá outras providências. Diário Oficial da União 1973; 17 jan.

19. Lyra Junior DP, Prado MCTA, Abriata JP, Pelá IR. Prescription orders as cause of risk of drug-related problems. Seguim Farmacoter 2004; 2:86-96.

20. Gimenes FRE, Miasso AI, Lyra Junior DP, Grou CR. Electronic prescription as contributory factor for hospitalized patients' safety. Pharmacy Practice 2006; 4:13-7.

21. Shulman R, Singer M, Goldstone J, Bellingan G. Medication errors: a prospective cohort study of hand-written and computerised physician order entry in the intensive care unit. Crit Care 2005; 9 ; R516-21.

22. Lisby M, Nielsen LP, Mainz J. Errors in the medication process: frequency, type, and potential. Int J Qual Health Care 2005; 17:15-22.

23. Organização Mundial da Saúde. Guia do instrutor em práticas da boa prescrição médica. Genebra: Organização Pan-Americana da Saúde; 2001.

24. National Coordinating Council for Medication Error Reporting and Prevention. Recommendations to enhance accuracy of prescription writing, 2005. http://www.nccmerp.org (accessed on 12/ Nov/2007).

25. Fontan JE, Maneglier V, Nguyen VX, Loirat C, Brion F. Medication errors in hospitals: computerized unit dose drug dispensing system versus ward stock distribution system. Pharm World Sci 2003; 25:112-7.

26. Kalmeijer MD, Holtzer W, van Dongen R, Guchelaar HJ. Implementation of a computerized physician medication order entry system at the Academic Medical Centre in Amsterdam. Pharm World Sci 2003; 25:88-93.

27. Koppel R, Metlay JP, Cohen A, Abaluck B, Localio AR, Kimmel SE, et al. Role of computerized physician order entry systems in facilitating medication errors. JAMA 2005; 293:1197-203.

28. Lesar TS. Medication prescribing error reporting and prevention program: a 14-year experience. Medscape Pharmacists 2000; 1:1-28.
29. Cohen MR. Preventing medications errors related to prescribing. In: Cohen MR, editor. Medication errors causes, prevention, and risk management. Washington DC: American Pharmaceutical Association; 2000. p. 88.1-8.23.

30. Louro E, Romano-Lieber NS, Ribeiro E. Eventos adversos a antibióticos em pacientes internados em um hospital universitário. Rev Saúde Pública 2007; 41:1042-8.

31. Vaida AJ, Peterson J. Incomplete directions can lead to dispensing errors. Pharmacy Times 2002; 5:34-8.

32. Scarsi KK, Fotis MA, Noskin GA. Pharmacist participation in medical rounds reduces medication errors. Am J Health Syst Pharm 2002; 59:2089-92.

33. Davis NM. Medical abbreviations: 15,000 conveniences at the expense of communications and safety. Huntington Valley: Neil M. Davis Associates; 2001.

34. Benjamin DM. Reducing medication errors and increasing patient safety: case studies in clinical pharmacology. J Clin Pharmacol 2003; 43:768-83.

35. Cassiani SHB, Freire CC, Gimenes FRE. A prescrição médica eletrônica em um hospital universitário: falhas de redação e opiniões de usuários. Rev Esc Enferm USP 2003; 37:51-60.

36. Agência Nacional de Vigilância Sanitária. Consulta pública nº. 50. Dispõe sobre o Vocabulário Controlado de Formas Farmacêuticas. Diário Oficial da União 2007; 30 mai.

37. Joint Commission on Accreditation of Healthcare Organizations. National patient safety goals for 2006. http://www.jointcommission.org/General Public/NPSG/06_gp_npsg.htm (accessed on 22/ May/2006).

38. Institute for Safe Medication Practices. Special issue: do not use these dangerous abbreviations or dose designations, 2005. http://www.ismp.org/ Newsletters/acutecare/articles/20030220_2.asp (accessed on 12/Nov/2007).

39. Pedersen CA, Schneider PJ, Scheckelhoff DJ. ASHP National Survey of Pharmacy Practice in Hospital Settings: prescribing and transcribing - 2004. Am J Health-Syst Pharm 2005; 62:378-90.

40. Conselho Federal de Medicina. Código de ética médica, 1998. http://www.portalmedico.org.br/ index.asp?opcao=codigoetica\&portal (acessed on 12/Jan/2007)

41. Bates DW, Teich J, Lee J, Seger D, Kuperman G, Maluf N, et al. The impact of computerized physician order entry on medication error prevention. J Am Med Inform Assoc 1999; 6:313-21.

42. Kaushal R, Barker KN, Bates DW. How can information technology improve patient safety and reduce medication errors in children's health care? Arch Pediatric Adolesc Med 2001; 55:1002-6.

Submitted on 15/Aug/2006

Final version resubmitted on $04 / \mathrm{Mar} / 2008$

Approved on 24/Mar/2008 